\title{
Understandings, Attitudes, and Barriers About Diabetes Care: Analysis of Factors Influencing Community Pharmacists in China
}

\section{Jia Wang \\ Yuyao Pei \\ Feng Yu D \\ Zhen Kang \\ Yufen Zheng}

Department of Basic Medicine and Clinical Pharmacy, China Pharmaceutical University, Nanjing, Jiangsu Province, People's Republic of China
Correspondence: Yufen Zheng Department of Basic Medicine and Clinical Pharmacy, China Pharmaceutical University, Longmian Road No. 639,

Nanjing, Jiangsu Province, People's

Republic of China

Tel +86 I3218080696

Email cathy852I@hotmail.com
Purpose: Diabetes mellitus (DM) has been known as a major chronic health problem in China. Suboptimal management of diabetic patients may incur serious complications, even death. The quality of post-hospital care has a good relationship with community pharmacists. However, data describing the current situation from care between community pharmacists and patients in China are lacking. Our article is to investigate community pharmacists' activities, evaluate their attitudes towards providing diabetes care, assess their understandings, and identify perceived barriers.

Methods: A survey divided into four parts was carried out randomly in China. The part of basic characteristics, understandings, and pharmacists' perceived barriers was rated with a few listed choices scales, while the Likert scale was used to identify on the part of attitudes. Quantitative data were shown in frequency and valid percent. One-way analysis of variance (ANOVA) and non-parametric test conducted on data. A P-value $\leq 0.05$ was considered statistically significant.

Results: A total of 737 surveys were collected. The respondent pharmacists maintained a simply moderate understanding of diabetes care and the pharmaceutical services provided met basic needs rather than clinical ones, though they showed a good momentum towards providing better service. The respondent pharmacists considered patients lacking knowledge on self-management, shortage of funds as the main barriers.

Conclusion: Efforts are supposed to make to expand pharmacists' scope of practice, lessen patients' reluctance, and create platforms for pharmacists receiving further education.

Keywords: diabetes, community pharmacy, general practice, attitudes, barriers

\section{Plain Language Summary}

- China has a great population of patients suffering from diabetes mellitus. Community pharmacists still have huge room to play in the community management of diabetic patients. At present, there is insufficient research on community pharmacists for diabetes management, and it is necessary for us to investigate the development status first.

- In this research, we try our best to expand the scope of the investigation to the entire country to make the data sufficiently representative and persuasive. We conducted a comprehensive survey on the quality of community pharmacists, their awareness of diabetes and community disease management, and expectations for the future.

- Community pharmacists still need multiple efforts from themselves and the external society to achieve the desired level of diabetes management. Community pharmacists need to learn more professional knowledge and receive more professional training. 
Diabetic patients need to enter the community more boldly to accept management. Society needs to provide more policy publicity and material support. Of course, community pharmacists as a whole have full confidence in the future of diabetes community management. Community pharmacists in China will have an irreplaceable role in diabetes care sooner or later.

\section{Introduction}

It is estimated 451 million people were suffering from diabetes in 2017 compared to 415 million in 2015 . $^{1,2}$ In China, the latest epidemiological data shows that the prevalence of diabetes among adults is $10.4 \%{ }^{3}$ Besides, of all people with diabetes, only $37 \%$ have been officially diagnosed and $35.6 \%$ are receiving treatment. ${ }^{4}$ Less than $35 \%$ of the patients treated are effectively controlled for blood glucose. ${ }^{5}$ As a chronic disease affecting such a massive population, series of complications and poor adherence to therapy lead to health deterioration and add up to unnecessary expenditures easily, eventually compromising patients' quality of life. ${ }^{6}$ According to NDEP National Diabetes Survey: 2016, both the proportion of person with diabetes who lived with hypertension was $40 \%{ }^{7}$ Around $50 \%$ of patients reported poor adherence to their regimens. ${ }^{8}$ In China, more than $70 \%$ of person with diabetes die from cardiovascular and cerebrovascular diseases. The overall prevalence of lower extremity arterial disease reported in the certain study was $21.2 \%$. ${ }^{9}$ The prevalence of retinopathy and vision-deteriorating retinopathy is $27.9 \%$ and $12.6 \%$, respectively. ${ }^{10}$ Confronting these urgent matters, community pharmacists are good candidates to continuously support the proper provision of diabetes care outside the institutional setting. ${ }^{11}$ Undoubtedly, more and more efforts and positive impacts of pharmacists on improving diabetes or its co-morbidities management have been recognized. ${ }^{12}$ Pharmacists can play the following roles in the comprehensive management of diabetic patients, including improving patient medication compliance, ensuring the rationality of patients' home medication, providing medication education for patients, and participating in medication monitoring for diabetic patients. ${ }^{13-15}$ Study results from primary literature have shown that the involvement of pharmacists in direct patient care yields additional average $\mathrm{HbAlc}$ reductions of $0.88 \%-1.8 \%$, average systolic blood pressure reductions of $5.7-7.8 \mathrm{mmHg}$, and average low-density lipoprotein (LDL) reductions of $6.3 \mathrm{mg} / \mathrm{dL}-18.7 \mathrm{mg} / \mathrm{dl}$, compared with standard care. ${ }^{16,17}$ Also, the continuous intervention of the pharmacist is a cost-effective administration method, which improved the quality of life without any increase in spending. Furthermore, spending on controlling the process of illness deterioration was saved at the same time. ${ }^{18}$ Pharmacists can also assist in identifying asymptomatic diabetic patients. For example, in all community pharmacies in Thailand, the screening process employed risk prediction tools developed by Aekplakorn to select individuals who are at high risk for capillary blood glucose. Similar screening tools are promoting in Western, Oman, India, Japan. ${ }^{15}$

In China, around 400,000 pharmacists practice in community pharmacies. ${ }^{4}$ Not restricted in the traditional model, community pharmacists can also play a significant role in raising community awareness on risk factors and the importance of a healthy lifestyle. The emerging diabetes epidemic represents a significant demand for pharmacists to devote to diabetes care. The study aims to describe Chinese community pharmacists' attitudes and care they routinely provide to patients, to measure their diabetes knowledge, and to assess their perceived barriers. Eventually, results are summarized as references to establish official and standardized systems to evaluate the quality of diabetes care.

\section{Materials and Methods Study Design and Data Source}

From June to July 2019, a survey of a random sample of community pharmacists was conducted randomly in China. Pharmacists working in the community setting were eligible to participate in the study. Respondents covered different regions of China. All participants completed the questionnaire online through a link created by a questionnaire website, the questionnaire star.

In practice, statisticians propose that the sample size should be 5-10 times the scale item. Based on the number of survey items, the questionnaire should include a minimum of 410 people.

\section{Questionnaire Design}

The design of the questionnaire mainly refers to Theoretical Domains Framework Version 2 and similar literature previously. ${ }^{19-21}$ As seen in the Supplementary Material, the whole questionnaire was divided into four parts.

The first section collected the social-demographic information, including region, educational background, work setting, etc. 
The second section examined the pharmacist's understanding of diabetes care by probing the practice frequency of each service. This part consisted of 23 questions measured with a 4-level scale. These questions covered but were not limited to education on patient self-management, services included in routine care, clinical counseling, and monitor of lab tests. These items were listed after a thorough literature review of guidelines and similar studies. ${ }^{7,20,22-25}$

The third section was comprised of 15 potential barriers and the pharmacists were requested to choose the degree of the hindrance. Each of these was measured with a 5-level scale ranging.

The last section evaluated pharmacist's attitudes towards diabetes care on a 5-point Likert scale. For positive events, the choice of strongly agree scores 5 points; for negative events, strongly disagree scores 5 points.

\section{Statistical Analysis}

Data were entered into the SPSS, version 23 for analysis. Considering the specificity of certain questions, partially completed surveys were also included in the analysis. In this study, the alpha reliability coefficient method was used to test the reliability of the questionnaire, and the KMO test and Bartley sphere test were used to test the validity. The result of the test in Table 1 shows good reliability and validity. Demographic data were analyzed using frequencies and valid percentages (Table 2). Choices of the other three parts use the same presentation form for descriptive analysis (Tables 3,Tables 4-5). ANOVA and non-parametric test analysis were conducted on four factors related to the categorical data. Statistical significance was accepted at $p<0.05$.

\section{Results}

From June to July 2019, a total of 737 responses were collected. All results were submitted online. And all

Table I Test of Reliability and Validity

\begin{tabular}{|l|l|}
\hline $\begin{array}{l}\text { Alpha Reliability Coefficient } \\
\text { Cronbach Alpha }\end{array}$ & 0.856 \\
Number of items & 63 \\
\hline $\begin{array}{l}\text { KMO Test } \\
\text { KMO measure of sampling adequacy }\end{array}$ \\
\hline Bartley Spheroid Test & 0.929 \\
Approximate Chi-square & \\
F & $24,536.018$ \\
Statistical significance (P) & 2016 \\
\hline
\end{tabular}

Table 2 Characteristics of Participant Pharmacist

\begin{tabular}{|c|c|}
\hline Characteristics & N (Valid Percent) \\
\hline \multicolumn{2}{|l|}{ Sex } \\
\hline Male & 87 (II.8\%) \\
\hline Female & $648(88.2 \%)$ \\
\hline \multicolumn{2}{|l|}{ Region } \\
\hline Central & $104(14.1 \%)$ \\
\hline North & $63(8.6 \%)$ \\
\hline East & $281(38.2 \%)$ \\
\hline South & $82(11.2 \%)$ \\
\hline Northwest & $89(12.1 \%)$ \\
\hline Northeast & $29(3.9 \%)$ \\
\hline Southwest & 87 (1I.8\%) \\
\hline Professional pharmacist & $605(82.8 \%)$ \\
\hline \multicolumn{2}{|l|}{ Years of getting a licensed pharmacist certificate } \\
\hline$<5$ & $311(42.2 \%)$ \\
\hline $6-10$ & $188(25.5 \%)$ \\
\hline $11-15$ & $51(6.9 \%)$ \\
\hline$>15$ & $42(5.7 \%)$ \\
\hline \multicolumn{2}{|l|}{ Years of experience as community pharmacists } \\
\hline$<5$ & $192(26.1 \%)$ \\
\hline $6-10$ & $242(32.8 \%)$ \\
\hline $11-15$ & $170(23.1 \%)$ \\
\hline $16-20$ & $83(11.3 \%)$ \\
\hline$>20$ & $48(6.5 \%)$ \\
\hline \multicolumn{2}{|l|}{ Weekly working hours } \\
\hline$<8$ & $71(9.6 \%)$ \\
\hline $8-24$ & $15 \mathrm{I}(20.5 \%)$ \\
\hline $25-40$ & $166(22.5 \%)$ \\
\hline$>41$ & $343(46.5 \%)$ \\
\hline \multicolumn{2}{|l|}{ Major } \\
\hline Pharmacy & $385(52.2 \%)$ \\
\hline Clinical & $94(12.8 \%)$ \\
\hline Nursing & $32(4.3 \%)$ \\
\hline Traditional Chinese Medicine & $159(21.6 \%)$ \\
\hline Other medicine related majors & $67(9.1 \%)$ \\
\hline \multicolumn{2}{|l|}{ Education level } \\
\hline Specialist (college and secondary school) & $438(69.4 \%)$ \\
\hline Bachelor & $291(39.5 \%)$ \\
\hline Master (above) & $7(0.7 \%)$ \\
\hline \multicolumn{2}{|l|}{$\begin{array}{l}\text { Average number of pharmacists in the } \\
\text { pharmacy at any one shift }\end{array}$} \\
\hline 0 & $24(3.3 \%)$ \\
\hline I & $408(55.4 \%)$ \\
\hline$>1$ & $293(39.8 \%)$ \\
\hline \multicolumn{2}{|l|}{ Practice setting } \\
\hline Chain community pharmacy & $610(82.8 \%)$ \\
\hline Independent community pharmacy & $31(4.2 \%)$ \\
\hline
\end{tabular}

(Continued) 
Table 2 (Continued).

\begin{tabular}{|l|l|}
\hline Characteristics & N (Valid Percent) \\
\hline $\begin{array}{l}\text { Public health care ambulatory clinic pharmacy } \\
\text { Private health care ambulatory clinic pharmacy }\end{array}$ & $8(1.1 \%)$ \\
Others & $84(11.4 \%)$ \\
\hline $\begin{array}{l}\text { Willing to participant in diabetes training and/ } \\
\text { or continuing professional education activities }\end{array}$ & $641(87 \%)$ \\
\hline $\begin{array}{l}\text { Interest in receiving diabetes specific training } \\
\text { and or continuing professional education } \\
\text { activities in the future }\end{array}$ & $702(95.3 \%)$ \\
\hline Approximate percentage of diabetic patients & \\
0 & $4(0.6 \%)$ \\
\hline $\begin{array}{l}10 \\
25\end{array}$ & $224(31.4 \%)$ \\
50 & $247(34.6 \%)$ \\
75 & $167(23.4 \%)$ \\
I00 & $68(9.5 \%)$ \\
\hline Availability of anti-diabetic medications in the & $7(0.6 \%)$ \\
pharmacy & $717(97.3 \%)$ \\
\hline Availability of diabetic supplies and/or & $621(84.3 \%)$ \\
supplements in the pharmacy & $558(75.7 \%)$ \\
\hline Set up a patient file & \\
\hline
\end{tabular}

questionnaires have been filled out, and there are no missing answers.

\section{Characteristics of Pharmacists}

648 respondents $(88.2 \%)$ were female. The majority worked in eastern and central regions. Over 600 participants had obtained licenses. $67.7 \%$ of them had got licenses in the past decade which was compatible with their work duration. Most participants worked in chain pharmacies, while only about 5\% working in independent pharmacies. $46.5 \%$ of participants followed a full-time schedule, providing diabetes service weekly for more than 40 hours. $69.4 \%$ and $40.2 \%$ of participants held a secondary education diploma and a higher education degree, respectively. Most pharmacies were provided with necessary auxiliary diabetes testing devices. 702 respondents $(95.3 \%)$ planned to receive specialized diabetes training.

\section{Understanding of Diabetes Care}

The majority of pharmacists often stressed the importance of a healthy lifestyle and self-monitoring of glucose, which was known as two of the most important recommendations in guidelines. ${ }^{3}$ Similarly, educating patients on matters of hypoglycemia was seen in two-thirds of scenarios. Regarding medication counseling, the majority of pharmacists always suggested to patients the appropriate time to take medication and side effects. As a special medication with hypoglycemia risk, insulin requires special guidance. Therefore, the importance of insulin counseling in great detail cannot be emphasized enough. More than two-thirds of pharmacists offered information on the use and storage of insulin. 377 of respondents informed patients of the mechanism of insulin and the key differences amongst formulations. Additionally, Complication management constituted a critical part of the inpatient care process. Around 60\% highlighted the importance of screening for nephropathy, retinopathy, and neuropathy. As relevant monitoring parameters, blood pressure and cholesterol targets were emphasized by $84 \%$ and $73 \%$ of pharmacists respectively. Meanwhile, the percentage of practitioners educating patients on practicing foot care and recommending anti-platelet therapy was smaller only with $53 \%$ and $42 \%$. Lastly and unexpectedly, education on the importance of receiving influenza and pneumococcal pneumonia immunization was integrated into practice by less than $35 \%$ of pharmacists.

\section{Perceived Barriers for Diabetes Care}

The top three perceived barriers for providing diabetes services were patients' lack of knowledge on selfmanagement $(70 \%, \mathrm{n}=516 / 737)$, shortage of funding $(59.7 \%, \mathrm{n}=440 / 737)$, and inadequacy of professional staff $(56.9 \%, n=419 / 737)$. The low frequency of pharmacy visiting placed a negative impact on service promotion and spread. Having limited access to patients' comprehensive medical profiles and professional training after graduation restrained their ability to provide appropriate service. Last but not least, the absence of specific private counseling areas depressed the ongoing evolution.

\section{Attitudes Towards Diabetes Care}

Overall, pharmacists had positive attitudes towards managing diabetes. They supported the need for diabetes care to be popularized, given the serious consequences following complications and medication-related problems. Also, they agreed with community pharmacists taking responsibility for screening pre-diabetic patients and complications and then initiating care as early as possible accordingly. Nearly $90 \%$ of practitioners upheld that implementing diabetes management can enhance the recognition and value of this profession in society. Also, the total score presents 
Table 3 Understandings of Diabetes Care, Including Daily Activities

\begin{tabular}{|c|c|c|c|c|c|}
\hline Items & Never $^{a}$ & Rarely ${ }^{\mathbf{b}}$ & Often $^{c}$ & Always ${ }^{d}$ & $\mathbf{P}^{*}$ \\
\hline $\begin{array}{l}\text { Counsel on the use of blood glucose meters including how to obtain a blood } \\
\text { sample and how to interpret results }\end{array}$ & $23(3.2 \%)$ & $165(22.6 \%)$ & $344(47.1 \%)$ & $198(27.1 \%)$ & 0.003 \\
\hline Evaluate blood glucose log for values outside target range & 81 (11.1\%) & $291(40.0 \%)$ & $264(36.3 \%)$ & 91 (12.5\%) & 0.000 \\
\hline Counsel about signs, symptoms, causes and treatment of hypoglycemia & $20(2.8 \%)$ & $210(28.9 \%)$ & $325(44.7 \%)$ & $172(23.7 \%)$ & 0.005 \\
\hline Counsel on when to contact the health care provider & $11(1.5 \%)$ & $167(23.0 \%)$ & $365(50.2 \%)$ & $184(25.3 \%)$ & 0.186 \\
\hline Review the patient's drug refill history to identify poor adherence & $32(4.4 \%)$ & $245(33.7 \%)$ & $332(45.6 \%)$ & $119(16.3 \%)$ & 0.053 \\
\hline Provide specific interventions to help improve adherence & $38(5.2 \%)$ & $237(32.7 \%)$ & $338(46.6 \%)$ & $112(15.4 \%)$ & 0.414 \\
\hline Counsel on the appropriate handling and storage of insulin & $39(5.4 \%)$ & $160(22.0 \%)$ & $282(38.7 \%)$ & 247 (33.9\%) & 0.000 \\
\hline $\begin{array}{l}\text { Counsel on the appropriate use of insulin pens, syringes, lancets and needles } \\
\text { (eg, sharp disposal) }\end{array}$ & $45(6.2 \%)$ & $176(24.1 \%)$ & $259(35.5 \%)$ & $249(34.2 \%)$ & 0.000 \\
\hline $\begin{array}{l}\text { Counsel on how insulin works and the key differences amongst insulin } \\
\text { formulations }\end{array}$ & $72(9.9 \%)$ & $279(38.3 \%)$ & $247(33.9 \%)$ & 130 (17.9\%) & 0.000 \\
\hline $\begin{array}{l}\text { Counsel on appropriate insulin administration (mixing insulin, injection } \\
\text { technique, injection time) }\end{array}$ & $51(7.0 \%)$ & $200(27.4 \%)$ & $280(38.4 \%)$ & $198(27.2 \%)$ & 0.029 \\
\hline Describe the appropriate time to administer each oral anti-diabetic drug & $9(1.2 \%)$ & $126(17.3 \%)$ & $333(45.7 \%)$ & $260(35.7 \%)$ & 0.059 \\
\hline Counsel about the side effects of oral anti-diabetic drugs & $12(1.6 \%)$ & $183(25.1 \%)$ & $356(48.8 \%)$ & $179(24.5 \%)$ & 0.508 \\
\hline $\begin{array}{l}\text { Counsel on current recommendations for antiplatelet therapy (eg, low dose } \\
\text { Aspirin) }\end{array}$ & $113(15.6 \%)$ & $303(41.8 \%)$ & $243(33.5 \%)$ & $66(9.1 \%)$ & 0.181 \\
\hline $\begin{array}{l}\text { Provide education on the importance of controlling blood pressure in } \\
\text { diabetes }\end{array}$ & $8(1.1 \%)$ & 101 (13.9\%) & $365(50.1 \%)$ & $254(34.9 \%)$ & 0.808 \\
\hline Discuss the importance of self-testing of blood glucose levels & $7(1.0 \%)$ & $83(11.5 \%)$ & $35 \mathrm{I}(48.5 \%)$ & $282(39.0 \%)$ & 0.512 \\
\hline Counsel on the current treatment targets for cholesterol in diabetes & $28(3.9 \%)$ & $160(22.0 \%)$ & $333(45.9 \%)$ & $205(28.2 \%)$ & 0.398 \\
\hline Provide education on the importance of regular screening for retinopathy & $48(6.6 \%)$ & $244(33.5 \%)$ & $293(40.2 \%)$ & $143(19.6 \%)$ & 0.121 \\
\hline Provide education on the importance of regular screening for nephropathy & $42(5.8 \%)$ & 232 (31. 8\%) & $316(43.3 \%)$ & $139(19.1 \%)$ & 0.262 \\
\hline Provide education on the importance of regular screening for neuropathic pain & $63(8.7 \%)$ & $242(33.4 \%)$ & $296(40.8 \%)$ & $124(17.1 \%)$ & 0.168 \\
\hline Counsel on good foot care techniques & $76(10.5 \%)$ & $265(36.5 \%)$ & 261 (35.9\%) & $125(17.2 \%)$ & 0.666 \\
\hline $\begin{array}{l}\text { Provide education about the importance of immunization for influenza and } \\
\text { pneumococcal injection time) }\end{array}$ & $170(23.4 \%)$ & $299(41.1 \%)$ & $180(24.8 \%)$ & $78(10.7 \%)$ & 0.205 \\
\hline Describe the appropriate time to administer each oral anti-diabetic drug & $9(1.2 \%)$ & $126(17.3 \%)$ & $333(45.7 \%)$ & $260(35.7 \%)$ & 0.059 \\
\hline Counsel about the side effects of oral anti-diabetic drugs & $12(1.6 \%)$ & $183(25.1 \%)$ & $356(48.8 \%)$ & $179(24.5 \%)$ & 0.508 \\
\hline $\begin{array}{l}\text { Counsel on current recommendations for antiplatelet therapy (eg, low dose } \\
\text { Aspirin) }\end{array}$ & $113(15.6 \%)$ & $303(41.8 \%)$ & $243(33.5 \%)$ & $66(9.1 \%)$ & 0.181 \\
\hline $\begin{array}{l}\text { Provide education on the importance of controlling blood pressure in } \\
\text { diabetes }\end{array}$ & $8(1.1 \%)$ & 101 (13.9\%) & $365(50.1 \%)$ & $254(34.9 \%)$ & 0.808 \\
\hline Discuss the importance of self-testing of blood glucose levels & $7(1.0 \%)$ & $83(11.5 \%)$ & $35 \mathrm{I}(48.5 \%)$ & $282(39.0 \%)$ & 0.512 \\
\hline Counsel on the current treatment targets for cholesterol in diabetes & $28(3.9 \%)$ & $160(22.0 \%)$ & $333(45.9 \%)$ & $205(28.2 \%)$ & 0.398 \\
\hline Provide education on the importance of regular screening for retinopathy & $48(6.6 \%)$ & $244(33.5 \%)$ & $293(40.2 \%)$ & $143(19.6 \%)$ & 0.121 \\
\hline Provide education on the importance of regular screening for nephropathy & $42(5.8 \%)$ & $232(31.8 \%)$ & $316(43.3 \%)$ & $139(19.1 \%)$ & 0.262 \\
\hline Provide education on the importance of regular screening for neuropathic pain & $63(8.7 \%)$ & $242(33.4 \%)$ & $296(40.8 \%)$ & $124(17.1 \%)$ & 0.168 \\
\hline Counsel on good foot care techniques & $76(10.5 \%)$ & $265(36.5 \%)$ & $26 \mid(35.9 \%)$ & $125(17.2 \%)$ & 0.666 \\
\hline $\begin{array}{l}\text { Provide education about the importance of immunization for influenza and } \\
\text { pneumococcal pneumonia }\end{array}$ & $170(23.4 \%)$ & $299(41.1 \%)$ & $180(24.8 \%)$ & $78(10.7 \%)$ & 0.205 \\
\hline Stress the importance of weight control in diabetes management where applicable & $8(1.1 \%)$ & $129(17.7 \%)$ & $367(50.3 \%)$ & $225(30.9 \%)$ & 0.169 \\
\hline Stress the importance of diet and regular exercise in diabetes management & $3(0.4 \%)$ & 87 (11.9\%) & $344(47.2 \%)$ & $295(40.5 \%)$ & 0.659 \\
\hline
\end{tabular}

Notes: ${ }^{a}$ This service is not provided to patients with diabetes. ${ }^{b}$ This service is provided to about $25 \%$ of patients with diabetes. ${ }^{c}$ This service is provided to about $75 \%$ of patients with diabetes. ${ }^{\mathrm{d}}$ This service is provided to about $100 \%$ of patients with diabetes. ${ }^{*}$ Result of $\chi 2$ test, dimensions according to different regions.

a normal distribution with the middle-high, and low sides.

The result of the total score expressed a positive attitude and confidence.

\section{Correlation Analysis}

To obtain further results, we build one-way analysis and non-parametric test to explore deeper correlation. We 
Table 4 Perceived Barriers for Providing Diabetic Care Services

\begin{tabular}{|c|c|c|c|c|c|c|}
\hline Items & $\begin{array}{l}\text { Strongly } \\
\text { Disagree }\end{array}$ & Disagree & Neutral & Agree & $\begin{array}{l}\text { Strongly } \\
\text { Agree }\end{array}$ & $\mathbf{P}^{*}$ \\
\hline $\begin{array}{l}\text { Providing chronic management service is not the main } \\
\mathrm{KPI} \text { of pharmacists }\end{array}$ & |3| (17.9\%) & $269(36.7 \%)$ & $188(25.5 \%)$ & $122(16.7 \%)$ & $22(3.0 \%)$ & 0.456 \\
\hline I do not have enough time & $21(2.8 \%)$ & $98(13.3 \%)$ & $259(35.1 \%)$ & $315(42.7 \%)$ & $44(6.0 \%)$ & 0.007 \\
\hline Shortage of personnel & $20(2.7 \%)$ & $64(8.7 \%)$ & $234(31.8 \%)$ & $352(47.8 \%)$ & $67(9.1 \%)$ & 0.397 \\
\hline I do not have a private counselling area & $14(1.9 \%)$ & $83(11.3 \%)$ & $245(33.2 \%)$ & $34 \mid(46.3 \%)$ & $54(7.3 \%)$ & 0.005 \\
\hline $\begin{array}{l}\text { Low patient expectations regarding pharmacists role in } \\
\text { diabetes }\end{array}$ & $30(4.1 \%)$ & III (I5.1\%) & $263(35.7 \%)$ & $269(36.5 \%)$ & $64(8.7 \%)$ & 0.167 \\
\hline Lack of diabetes related educational materials in the pharmacy & $24(3.3 \%)$ & 117 (15.9\%) & $249(33.8 \%)$ & $300(40.7 \%)$ & $47(6.4 \%)$ & 0.018 \\
\hline Lack of access to patients medical profiles & $13(1.8 \%)$ & $99(13.4 \%)$ & $217(29.4 \%)$ & $348(47.2 \%)$ & $60(8.1 \%)$ & 0.019 \\
\hline Lack of diabetes therapeutic knowledge and skills & $20(2.7 \%)$ & $116(15.7 \%)$ & $275(37.3 \%)$ & $288(39.1 \%)$ & $38(5.2 \%)$ & 0.155 \\
\hline Limited funding & $10(1.4 \%)$ & $46(6.2 \%)$ & $24 I(32.7 \%)$ & $366(49.7 \%)$ & $74(10.0 \%)$ & 0.122 \\
\hline Cultural or religious barriers & $36(4.9 \%)$ & 191 (25.9\%) & $345(46.8 \%)$ & 149 (20.2\%) & $16(2.2 \%)$ & 0.567 \\
\hline Lack of diabetic patients visiting the pharmacy & $14(1.9 \%)$ & $92(12.5 \%)$ & $346(46.9 \%)$ & 257 (34.9\%) & $28(3.8 \%)$ & 0.119 \\
\hline I am not interested in providing diabetes care & $55(7.5 \%)$ & $244(33.1 \%)$ & $306(41.5 \%)$ & $115(15.6 \%)$ & $17(2.3 \%)$ & 0.006 \\
\hline Language barrier & $64(8.7 \%)$ & $288(39.1 \%)$ & $324(44 \%)$ & 55 (7.5\%) & $6(0.8 \%)$ & 0.085 \\
\hline Lack of diabetes training programs for pharmacists & $20(2.7 \%)$ & $97(13.2 \%)$ & $246(33.4 \%)$ & $316(42.9 \%)$ & $58(7.9 \%)$ & 0.002 \\
\hline Low patient knowledge about diabetes management & $13(1.8 \%)$ & $28(3.8 \%)$ & $180(24.4 \%)$ & $423(57.4 \%)$ & $93(12.6 \%)$ & 0.305 \\
\hline
\end{tabular}

Note: ${ }^{*}$ Result of $\chi 2$ test, dimensions according to different regions.

Table 5 Attitude Towards Diabetic Care

\begin{tabular}{|c|c|c|c|c|c|c|}
\hline Items & $\begin{array}{l}\text { Strongly } \\
\text { Agree }\end{array}$ & Agree & Neutral & Disagree & $\begin{array}{l}\text { Strongly } \\
\text { Disagree }\end{array}$ & $\mathbf{P}^{*}$ \\
\hline $\begin{array}{l}\text { I think the practice of diabetic care is valuable.All patients } \\
\text { should be performed pharmaceutical care }\end{array}$ & $222(30.1 \%)$ & $345(46.8 \%)$ & 147 (19.9\%) & $19(2.6 \%)$ & $4(0.5 \%)$ & 0.408 \\
\hline $\begin{array}{l}\text { Primary responsibility of pharmacists should be to prevent and } \\
\text { solve medication-related problem and complications. }\end{array}$ & $180(24.4 \%)$ & $371(50.3 \%)$ & $148(20.1 \%)$ & $32(4.3 \%)$ & $6(0.8 \%)$ & 0.022 \\
\hline Providing diabetic care takes too much time and effort & $90(12.2 \%)$ & $327(44.4 \%)$ & $234(31.8 \%)$ & $82(11.1 \%)$ & $4(0.5 \%)$ & 0.628 \\
\hline Diabetic care is an extensio $o$ the community pharmacy services & I8I (24.6\%) & $458(62.1 \%)$ & $86(11.7 \%)$ & II (I.5\%) & $\mathrm{I}(0.1 \%)$ & 0.582 \\
\hline $\begin{array}{l}\text { Do you feel that conductingthese eye o foot screenings is a task } \\
\text { yo woul be willing to complete on a routine basis? }\end{array}$ & $86(11.7 \%)$ & $367(49.8 \%)$ & $232(31.5 \%)$ & $49(6.6 \%)$ & $3(0.4 \%)$ & 0.168 \\
\hline $\begin{array}{l}\text { Do you think the technology is useful to the patients at this } \\
\text { pharmacy? }\end{array}$ & 194 (26.3\%) & 475 (64.5\%) & 64 (8.7\%) & $2(0.3 \%)$ & $2(0.3 \%)$ & 0.065 \\
\hline $\begin{array}{l}\text { What positive aspects, if any, have you noticed about offering } \\
\text { this screening in the pharmacy? }\end{array}$ & 112 (I5.2\%) & $414(56.2 \%)$ & 190 (25.8\%) & I3 (I.8\%) & 8 (I.I\%) & 0.020 \\
\hline $\begin{array}{l}\text { What negative aspects, if any, have you noticed about offering } \\
\text { this screening in the pharmacy? }\end{array}$ & $22(3.0 \%)$ & 145 (19.7\%) & $264(35.8 \%)$ & 281 (38.1\%) & $25(3.4 \%)$ & 0.941 \\
\hline $\begin{array}{l}\text { Pharmaceutical care will increase the patient's appreciation of } \\
\text { the pharmacist's value and image }\end{array}$ & 204 (27.7\%) & 443 (60.1\%) & $80(10.9 \%)$ & $10(1.4 \%)$ & 0 & 0.947 \\
\hline $\begin{array}{l}\text { There are no economic benefits to be gained from } \\
\text { implementation of pharmaceutical care }\end{array}$ & 21 (2.8\%) & 107 (14.5\%) & $226(30.7 \%)$ & $326(44.2 \%)$ & 57 (7.7\%) & 0.024 \\
\hline
\end{tabular}

Note: ${ }^{*}$ Result of $\chi 2$ test, dimensions according to different regions.

divide dimensions according to different regions. Results in detail are shown in Table 6 .

\section{Discrepancy of Understandings of Diabetes Mellitus Care}

Results of ANOVA show that counselling on how insulin works and differences amongst insulin formulations varies especially in the South and Southwest regions. Also, diabetes mellitus patients' ratio and practice time have an impact on this point more or less. Likewise, pharmacists mostly emphasize the importance of weight control regardless of different regions. Furthermore, combining with non-parametric tests, the following descriptions can be concluded: 
Table 6 One-Way Analysis of Variance and Non-Parametric Test eg, Divide Dimensions According to Different Regions

\begin{tabular}{|c|c|c|c|}
\hline P value & ANOVA & KW Test & JT Test \\
\hline $\begin{array}{l}\text { Counsel on the use of blood glucose meters including how to obtain a blood sample and how to interpret } \\
\text { results }\end{array}$ & & 0.009 & 0.060 \\
\hline Evaluate blood glucose log for values outside target range & 0.000 & & \\
\hline Evaluate blood glucose log for values outside target range & & 0.304 & 0.891 \\
\hline Evaluate blood glucose log for values outside target range & & 0.268 & 0.887 \\
\hline Review the patient's drug refill history to identify poor adherence & 0.009 & & \\
\hline Provide specific interventions to help improve adherence & & 0.226 & 0.225 \\
\hline Counsel on the appropriate handling and storage of insulin & & 0.000 & 0.028 \\
\hline Counsel on the appropriate use of insulin pens, syringes, lancets and needles (eg, sharp disposal) & & 0.000 & 0.257 \\
\hline Counsel on how insulin works and the key differences amongst insulin formulations & 0.000 & & \\
\hline Counsel on appropriate insulin administration (mixing insulin, injection technique, injection time) & 0.005 & & \\
\hline Describe the appropriate time to administer each oral anti-diabetic drug & & 0.396 & 0.799 \\
\hline Counsel about the side effects of oral anti-diabetic drugs & & 0.138 & 0.233 \\
\hline Counsel on current recommendations for antiplatelet therapy (eg, low dose Aspirin) & 0.040 & & \\
\hline Provide education on the importance of controlling blood pressure in diabetes & & 0.991 & 0.697 \\
\hline Discuss the importance of self-testing of blood glucose levels & & 0.601 & 0.433 \\
\hline Counsel on the current treatment targets for cholesterol in diabetes & & 0.265 & 0.280 \\
\hline Provide education on the importance of regular screening for retinopathy & & 0.154 & 0.503 \\
\hline Provide education on the importance of regular screening for nephropathy & & 0.138 & 0.565 \\
\hline Provide education on the importance of regular screening for neuropathic pain & & 0.147 & 0.610 \\
\hline Counsel on good foot care techniques & & 0.116 & 0.539 \\
\hline Provide education about the importance of immunization for influenza and pneumococcal pneumonia & & 0.270 & 0.643 \\
\hline Stress the importance of weight control in diabetes management where applicable & & 0.574 & 0.291 \\
\hline Stress the importance of diet and regular exercise in diabetes management & & 0.476 & 0.516 \\
\hline Providing chronic management service is not the main KPI of pharmacists & & 0.473 & 0.437 \\
\hline I do not have enough time & & 0.003 & 0.194 \\
\hline Shortage of personnel & & 0.088 & 0.316 \\
\hline I do not have a private counselling area & 0.009 & & \\
\hline Low patient expectations regarding pharmacists role in diabetes care & 0.042 & & \\
\hline Lack of diabetes related educational materials in the pharmacy & 0.002 & & \\
\hline Lack of access to patients medical profiles & 0.022 & & \\
\hline Lack of diabetes therapeutic knowledge and skills & & 0.095 & 0.844 \\
\hline Limited funding & & 0.006 & 0.618 \\
\hline Cultural or religious barriers & & 0.817 & 0.030 \\
\hline Lack of diabetic patients visiting the pharmacy & & 0.156 & 0.074 \\
\hline I am not interested in providing diabetes care & & 0.092 & 0.087 \\
\hline Language barrier & & 0.077 & 0.644 \\
\hline Lack of diabetes training programs for pharmacists & 0.000 & & \\
\hline Low patient knowledge about diabetes management & & 0.241 & 0.194 \\
\hline
\end{tabular}

Pharmacists in different geographical areas behave differently in the education of using insulin and blood glucose meters.

Pharmacists with longer service time and more experiences spend more time on education on lifestyle and screening of blood pressure and cholesterol. Consistent with results of ANOVA, weight control, and foot care was highlighted more by pharmacists who have practiced for decades.
As the proportion of diabetes mellitus patients increases, pharmacists are more likely to focus on screening for complications and enhancing immunity.

The explanation of administrative matters and the screening of complications increase with the accumulation of practice time. The longer pharmacists work, the more comprehensive and patient-oriented the counseling was. Especially, the clear explanations on the appropriate time to administer each oral anti-diabetic drug and 
possible side effects had good relativity with practice time.

\section{Discrepancy of Barriers in Diabetes Mellitus Care}

Pharmacists spreading across different regions hold distinctive levels of lack of relevant training materials in the pharmacy and programs. In some areas, pharmacists believe that limited funding may become a major factor hindering the development of pharmaceutical services. Everyone is of the opinion that providing diabetes mellitus management services is not the main performance indicator. Besides, the shortage of personnel and professional skills are common shortcomings impeding better diabetes mellitus care.

\section{Discrepancy of Attitudes}

In terms of the total score of the Likert Scale, ANOVA results show that there are differences between shorter weekly work time groups and full-time groups. The longer the pharmacists work per week, the more the pharmacists agree with the opinion that diabetes management is an extension of community pharmacy services. In specialist clinics, pharmacists take more intervention in identifying and screening complications. Besides, they believe that professional diabetes mellitus management will increase patients' understanding of the value and image of pharmacists. As a result, implementing diabetes management will bring great economic benefits.

\section{Discussion}

\section{Summary}

This study proves that Chinese pharmacists mainly provide basic services for the people with diabetes patients and their involvement in advanced services is limited. They have an average knowledge level and are in aspiration for further training. Primary care services such as intervention in lifestyle and medication monitoring are well conducted in the community, which are consistent with previous survey. ${ }^{19,20,26,27}$ Their top perceived barriers include patients' lack of knowledge of self-management, shortage of funds, and the dearth of professional staff. Luckily, pharmacists express general positive attitudes. They are clear about primary responsibility. With the increasing popularity of diabetes care, the professional image of pharmacists and profit would improve. These results are in line with those of studies from Qatar, Canada, and the United States. ${ }^{16,20,28,29}$ The majority of pharmacists admit that more attention should be paid to the seriousness of complications, to the community pharmacists' responsibility, and to the importance of screening pre-diabetes.

\section{Implications for Research and Practice}

In general, community pharmacists working on diabetes mellitus care have a good background of education and can provide patient-centered services, though the team construction still has some room for improvement in several aspects. Similar to the results of this study, the results of the Qatar study show that more than half of the interviewed pharmacists have more than 5 years of work experience. ${ }^{20}$ The above results indicate that community pharmacists have a relatively high educational background and practical experience, and have a good foundation for completing diabetes community care.

\section{Economic and Policy Support Needs to Improve}

Most pharmacists come from an economically developed region. The current health care delivery model in community settings is not comprehensive and imbalanced. ${ }^{30}$ Benefiting from the better financial conditions and more advanced policies, pharmacists from central and east get used to monitoring glucose and take action to prevent hypoglycemia. Secondly, lacking funds is one of the biggest barriers. As a result, the shortage of funds brings deficiency of training materials and programs. To solve these problems, it is time for the government to implement positive policy to enlarge the investment in community pharmacy. Also, experienced pharmacists could guide underdeveloped areas or independent pharmacies. Or personnel in need are allowed to attend advanced studies. Benign communication and knowledge sharing contribute to a good loop to accelerate the growth on the whole.

\section{Devices Need to Be Strengthened}

The implement of diabetes mellitus care is inseparable from the rational allocation of resources. Thus providing more effective device support guarantees a better practice experience, leading to a sense of satisfaction. Similar research results show that lack of the work environmental context was one of the biggest barriers to routine monitoring and follow-up for people with diabetes. ${ }^{21}$ Only to improve this type of problem, more and more patients are willing to accept services from a community pharmacy. There is no doubt the value of pharmacists would obtain more recognition. And confidence and expectation lead to better services, forming a sustainable loop. 


\section{Qualification of Professional Talents Need to Raise}

In Canada, licensed Canadian pharmacists can become certified diabetes educators (CDE) after passing exams. Pharmacists may choose to either write a CDE exam or to accumulate 250 credits to maintain this title. Learning records can also be used to satisfy continuing education requirements to renew licenses. ${ }^{31}$

Obviously, in China, some community pharmacists have not passed standardized training. The low entry threshold leads to the insufficient scale of pharmacy talents. There is still room for improvement in the scale and professional level of pharmacists. A systematic review of pharmacies in South Asia showed that training is needed in the process of identifying pharmaceutical care problems because pharmacists are lacking experience in identifying and tackling care issues. ${ }^{15}$ Therefore, relevant government departments should combine the current situation to refine licensed pharmacists and regulations, and coordinate resources to provide a suitable environment. Given respondents' major, more and more students majoring in pharmacy and traditional medicine contribute to a specialized service team from a forward-looking perspective. Relevant training departments must fully consider each major ensuring to provide a strong guarantee for qualified talents and expand the training scale of pharmacy talents aiming at working in the community, especially specialized talents.

\section{Pharmacy Service Charges System Need to Build} Compared to dispensing medications, offering clinical customer services takes more time but produces fewer profits. In terms of services for the person with diabetes, Canadian pharmacists provide a Comprehensive Annual Care Plan and Standard Medication Management Assessment for 100 and 60 Canadian dollars respectively per patient annually. It is a great example of clinical services. By embodying the value of pharmacy services, it encourages personnel to enhance professional recognition, while improving the service quality.

\section{Specialized in Diabetes Mellitus' Care Needs to Be Stressed}

It is satisfied that $75.7 \%$ of pharmacists get used to documentation. However, it needs to be emphasized that education pertinent to immunization was rarely provided, though clinical practice guidelines recommend doing so. Studies in Australia and Canada have shown that pharmacists who underwent diabetes training provided more services relevant to diabetes management. ${ }^{26,32}$ So Pharmacists need to participate in continuing education courses and offer more advanced and comprehensive services. For example, community pharmacists in different provinces across Canada can provide medication review, assessment, and care plan services. ${ }^{31}$ Meanwhile, the results of the RCT study demonstrated that the medication review had a positive impact as well. There was better treatment compliance in the intervention group. ${ }^{14}$ Specializing in certain majors may display a higher level of understanding of comprehensive and advanced diabetes care. First, pharmacy students mostly learn about drug-related knowledge but not patient-centered clinical expertise. Consequently, though passing the licensing examination, they may not have comprehensive and systematic assessment approaches. The shift of the specific pharmacy education system from a drug-oriented to a pharmaceutical-care-oriented approach is required. ${ }^{33,34}$ Governors should pay attention to specialty training, at the same time feel the urgent requirement indeed.

\section{Strengths and Limitations}

This study is an experimental study. Due to the large number and complexity of the research object overall, it is difficult to achieve complete random. Secondly, the majority of pharmacists were the ones who worked in the eastern part, which may lead to a bias. Thirdly, only 700 pharmacists responded to the study. Results may not represent the whole portrait nationwide. To justify the result, an optimized questionnaire could be redesigned to involve more pharmacists.

\section{Conclusion}

This study proves that Chinese pharmacists mainly provide basic services for diabetic patients and their involvement in offering advanced diabetes services is limited. They have an average diabetes related knowledge level and are in aspiration for further diabetes related training and/or continuous educational activities. Their top perceived barriers for provision of diabetes care include patients' lack of knowledge of self-management shortage of fund and dearth of professional staff. Yet, pharmacists have overall positive attitudes toward taking part in diabetes management.

\section{Ethics Approval and Informed Consent}

All procedures were approved by the ethics committee of China Pharmaceutical University, in strict accordance with the guidelines set by the Bureau of Sciences and Techniques of Jiangsu Province, China. Participants in the survey all signed informed consent. 


\section{Acknowledgments}

This work was supported by the "China Pharmaceutical University's 2020 first-class curriculum cultivation and construction Phase 1" [3052000051]. The data used to support the findings of this study are included in the article.

\section{Author Contributions}

All authors made a significant contribution to the work reported, whether that is in the conception, study design, execution, acquisition of data, analysis and interpretation, or in all these areas; took part in drafting, revising or critically reviewing the article; gave final approval of the version to be published; have agreed on the journal to which the article has been submitted; and agree to be accountable for all aspects of the work.

\section{Disclosure}

The authors declare no conflicts of interest.

\section{References}

1. Cho NH, Shaw JE, Karuranga S, et al. IDF diabetes atlas: global estimates of diabetes prevalence for 2017 and projections for 2045. Diabetes Res Clin Pract. 2018;138:271-281. doi:10.1016/j.diabres. 2018.02.023

2. Ogurtsova K, da Rocha Fernandes JD, Huang Y, et al. IDF diabetes atlas: global estimates for the prevalence of diabetes for 2015 and 2040. Diabetes Res Clin Pract. 2017;128:40-50. doi:10.1016/j. diabres.2017.03.024

3. Weiping J. Standards of medical care for type 2 diabetes in China 2019. Diabetes Metab Res Rev. 2019;6(35).

4. Bo Z. Outlook for the epidemiology and prevention of diabetes in China. Chin J Diabetes Mellitus. 2019;1(11).

5. Weiping J. Strategic thinking on the prevention and treatment of diabetes complications in China. Chin J Diabetes Mellitus. 2019;8 (11).

6. Bommer C, Sagalova V, Heesemann E, et al. Global economic burden of diabetes in adults: projections from 2015 to 2030. Diabetes Care. 2018;41(5):963-970. doi:10.2337/dc17-1962

7. National Institute of Diabetes and Digestive and Kidney Diseases N. National diabetes education program: National Diabetes Survey (NNDS); 2016. Available from: https://www.niddk.nih.gov/healthinformation/health-statistics/diabetes-statistics/ndep-national-diabetes -survey. Accessed October 13, 2019.

8. Abughosh SM, Wang X, Serna O, et al. A pharmacist telephone intervention to identify adherence barriers and improve adherence among nonadherent patients with comorbid hypertension and diabetes in a medicare advantage plan. J Manag Care Spec Pharm. 2016;22(1):63-73. doi:10.18553/jmcp.2016.22.1.63

9. Zhang X, Ran X, Xu Z, et al. Epidemiological characteristics of lower extremity arterial disease in Chinese diabetes patients at high risk: a prospective, multicenter, cross-sectional study. J Diabetes Complications. 2018;32(2):150-156. doi:10.1016/j.jdiacomp.2017. 10.003

10. Zhang G, Chen H, Chen W, Zhang M. Prevalence and risk factors for diabetic retinopathy in China: a multi-hospital-based cross-sectional study. Br J Ophthalmol. 2017;101(12):1591-1595. doi:10.1136/ bjophthalmol-2017-310316
11. Xi X, Huang Y, Lu Q, Ung COL, Hu H. Community pharmacists' opinions and practice of pharmaceutical care at chain pharmacy and independent pharmacy in China. Int $J$ Clin Pharm. 2019;41 (2):478-487. doi:10.1007/s11096-019-00802-w

12. Chung AY, Anand S, Wong IC, et al. Improving medication safety and diabetes management in Hong Kong: a multidisciplinary approach. Hong Kong Med J. 2017;23(2):158-167. doi:10.12809/ hkmj165014

13. Chua SS, Kok LC, Yusof FA, et al. Pharmaceutical care issues identified by pharmacists in patients with diabetes, hypertension or hyperlipidaemia in primary care settings. BMC Health Serv Res. 2012;12(1):388. doi:10.1186/1472-6963-12-388

14. Moczygemba LR, Bhathena S, DiPiro CV, Snead R. Pharmacist documentation of gaps in care identified during diabetes coaching. J Am Pharm Assoc (2003). 2019;59(1):57-63. doi:10.1016/j.japh.20 18.09.002

15. Dwiputri AW, Pristianty L, Hermansyah A. Pharmacist contributions in the treatment of diabetes mellitus in Southeast Asia: a narrative review. J Basic Clin Physiol Pharmacol. 2020;30(6). doi:10.1515/ jbcpp-2019-0322

16. Chisholm-Burns MA, Kim Lee J, Spivey CA, et al. US pharmacists' effect as team members on patient care: systematic review and metaanalyses. Med Care. 2010;48(10):923-933. doi:10.1097/MLR.0b0 $13 \mathrm{e} 3181 \mathrm{e} 57962$

17. Tan EC, Stewart K, Elliott RA, George J. Pharmacist services provided in general practice clinics: a systematic review and meta-analysis. Res Social Adm Pharm. 2014;10(4):608-622. doi:10. 1016/j.sapharm.2013.08.006

18. Jamshed SQ, Siddiqui MJ, Rana B, Bhagavathula AS. Evaluation of the involvement of pharmacists in diabetes self-care: a review from the economic perspective. Front Public Health. 2018;6:244. doi:10.3389/fpubh.2018.00244

19. Wibowo Y, Parsons R, Sunderland B, Hughes J. Evaluation of community pharmacy-based services for type-2 diabetes in an Indonesian setting: pharmacist survey. Int J Clin Pharm. 2015;37(5):873-882. doi:10.1007/s11096-015-0135-y

20. El Hajj MS, Abu Yousef SE, Basri MA. Diabetes care in Qatar: a survey of pharmacists' activities, attitudes and knowledge. Int J Clin Pharm. 2018;40(1):84-93. doi:10.1007/s11096-017-0562-z

21. MacCallum L, Mathers A, Kellar J, et al. Pharmacists report lack of reinforcement and the work environment as the biggest barriers to routine monitoring and follow-up for people with diabetes: a survey of community pharmacists. Res Social Adm Pharm. 2021;17 (2):332-343. doi:10.1016/j.sapharm.2020.04.004

22. Lalonde L, Leroux-Lapointe V, Choiniere M, et al. Knowledge, attitudes and beliefs about chronic noncancer pain in primary care: a Canadian survey of physicians and pharmacists. Pain Res Manag. 2014;19(5):241-250. doi:10.1155/2014/760145

23. Law MG, Komura S, Murchison AP, Pizzi LT. Pharmacy staff opinions regarding diabetic retinopathy screenings in the community setting: findings from a brief survey. Am Health Drug Benefits. 2013;6(9):548-552.

24. Schoenmakers TW, Teichert M, Braspenning J, Vunderink L, De Smet PA, Wensing M. Evaluation of quality indicators for Dutch community pharmacies using a comprehensive assessment framework. J Manag Care Spec Pharm. 2015;21(2):144-152. doi:10.18553/jmcp.2015.21.2.144

25. Soprovich AL, Sharma V, Tjosvold L, Eurich DT, Johnson JA. Systematic review of community pharmacy-based and pharmacist-led foot care interventions for adults with type 2 diabetes. Can Pharm J. 2019;152(2):109-116. doi:10.1177/17151 63519826166

26. Patel T, Chang F, Mohammed HT, et al. Knowledge, perceptions and attitudes toward chronic pain and its management: a cross-sectional survey of frontline pharmacists in Ontario, Canada. PLoS One. 2016;11(6):e0157151. doi:10.1371/journal.pone.0157151 
27. Wibowo Y, Sunderland B, Hughes J. Pharmacist and physician perspectives on diabetes service delivery within community pharmacies in Indonesia: a qualitative study. Int J Pharm Pract. 2016;24 (3):180-188. doi:10.1111/ijpp.12227

28. Langran T, Nanda N, Bataveljic A, Gonzalez-Durio J. Supporting the management of type 2 diabetes with pharmacist-led reviews: an observational analysis. BMJ Open. 2017;7(3):e013451. doi:10.1136/ bmjopen-2016-013451

29. Shatnawi A, Latif DA. A qualitative assessment of West Virginia pharmacist activities and attitude in diabetes management. $J$ Eval Clin Pract. 2017;23(3):586-592. doi:10.1111/jep.12677

30. Siaw MYL, Ko Y, Malone DC, et al. Impact of pharmacist-involved collaborative care on the clinical, humanistic and cost outcomes of high-risk patients with type 2 diabetes (IMPACT): a randomized controlled trial. J Clin Pharm Ther. 2017;42(4):475-482. doi: $10.1111 /$ jcpt. 12536
31. Cross. AB. Alberta blue cross pharmaceutical services-A pharmacist's guide to pharmacy services compensation; 2018. Available from: https://www.ab.bluecross.ca/pdfs/83443_compensation_guide. pdf. Accessed November 13, 2019.

32. Jorgenson D, Penm J, MacKinnon N, Smith J. A needs assessment of community pharmacists for pharmacist specialization in Canada. Int J Pharm Pract. 2017;25(2):159-167. doi:10.1111/ijpp.12297

33. Liu J, Wang J, Hu XM. Knowledge, perceptions, and practice of ecopharmacovigilance among pharmacy professionals in China. Environ Monit Assess. 2017;189(11):552. doi:10.1007/s10661-017-6289-4

34. Prudencio J, Cutler T, Roberts S, Marin S, Wilson M. The effect of clinical pharmacist-led comprehensive medication management on chronic disease state goal attainment in a patient-centered medical home. J Manag Care Spec Pharm. 2018;24(5):423-429. doi:10.18553/jmcp.2018.24.5.423

\section{Publish your work in this journal}

Diabetes, Metabolic Syndrome and Obesity: Targets and Therapy is an international, peer-reviewed open-access journal committed to the rapid publication of the latest laboratory and clinical findings in the fields of diabetes, metabolic syndrome and obesity research. Original research, review, case reports, hypothesis formation, expert opinion and commentaries are all considered for publication. The manuscript management system is completely online and includes a very quick and fair peer-review system, which is all easy to use. Visit http://www.dovepress.com/testimonials.php to read real quotes from published authors. 